\title{
Obama calls for calm as US ramps up domestic Ebola response
}

\author{
Michael McCarthy
}

Seattle

In his weekly address to the nation, 18 October, President Barack Obama told Americans that the diagnosis of three cases of Ebola virus disease in the United States did not mean that the country faced an outbreak or epidemic of the disease.

"This is a serious disease," Obama said, "but we can't give in to hysteria or fear, because that only makes it harder to get people the accurate information they need. We have to be guided by the science."

The first case involved Thomas Eric Duncan, a Liberian national, who fell ill with the disease shortly after he arrived in Dallas, Texas, from west Africa in late September. After 11 days in hospital Duncan died 8 October. ${ }^{1}$

Shortly afterward the disease was diagnosed in two nurses who cared for him. They are now undergoing treatment in specialized isolation units, one at Emory University Hospital in Atlanta, Georgia, and the other at the National Institutes of Health Clinical Center in Bethesda, Maryland. ${ }^{2}$

Noting that five Americans who were flown back to the US after contracting Ebola virus disease in west Africa have been successfully treated for the disease, Obama said, "We know how to fight this disease. We know the protocols. And we know that when they're followed, they work."

The president's speech came at the end of a week in which he took several steps to ramp up the country's domestic response to the Ebola epidemic. On Wednesday 15 October Obama directed the US Centers for Disease Control and Prevention to create an expert "SWAT team" to be ready to be deployed to any US hospital with a suspected case of Ebola virus disease within hours. ${ }^{3}$

The next day Obama reversed an earlier position and appointed an "Ebola tsar" to coordinate the US's Ebola response. The appointee, Rob Klain, a lawyer who previously served as chief of staff to the vice presidents Joe Biden and Al Gore, is not medically trained but is said to be an experienced crisis manager with extensive contacts through the federal government.

However, Obama rejected calls by many Republicans and some Democrats to ban air travel between the US and the west African countries affected by the outbreak. He said, "Trying to seal off an entire region of the world-if that were even possible — could actually make the situation worse. It would make it harder to move health workers and supplies back and forth. Experience shows that it could also cause people in the affected region to change their travel, to evade screening, and make the disease even harder to track."

The infections among US healthcare workers have led health officials to rethink their approach to the virus, said Anthony Fauci, director of the National Institute of Allergy and Infectious Diseases at the National Institutes of Health. Speaking on the ABC Sunday television news program This Week Fauci said, "I think this idea that every single hospital can take care of a seriously ill Ebola patient right now is just not true." Patients who present to community hospitals will now be transported to medical centers that have better facilities and have specially trained staff, Fauci said.

US health officials are also revising their protocols for handling patients with the disease, Fauci said. Current recommendations were based on World Health Organization protocols, which are appropriate for care provided in remote areas but do not offer enough protection to medical staff performing more advanced care, such as intubation, Fauci said.

In Dallas 48 people were being taken off health officials' watch list Sunday after having gone without developing symptoms for 21 days, the incubation period for Ebola virus disease, since they had been in contact with Duncan. "They'll be free to go," said county judge Clay Jenkins, Dallas County's chief executive and its director of homeland security and emergency management.

Several hundred people, however, continued to be monitored for signs and symptoms of infection, including more than 70 healthcare workers at the Dallas hospital that cared for Duncan and hundreds of passengers who were aboard two airplane flights taken by the second nurse shortly before her infection was diagnosed.

1 McCarthy M. Liberian man being treated for Ebola in Texas dies. BMJ 2014;349:96145. McCarthy M. Second US nurse with Ebola had traveled by plane. BMJ 2014:349:96277. McCarthy M. US deploys rapid response teams to hospitals with Ebola cases. BMJ 2014;349:g6266

Cite this as: $B M J$ 2014;349:g6333

๑ $\odot$ BMJ Publishing Group Ltd 2014 